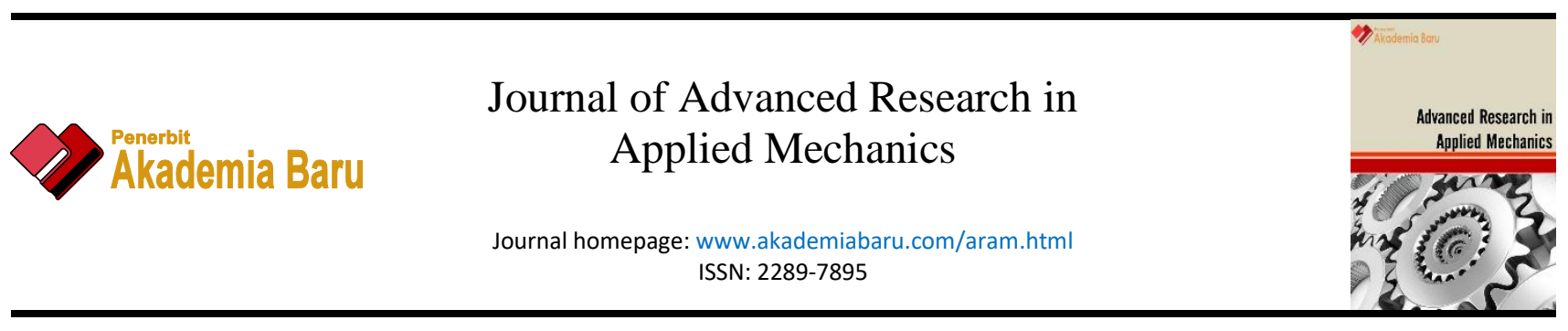

\title{
Estimation of Rotating Unbalance in Rotor Bearing System using Operating Deflection Shape
}

\author{
Mya Thet Hnin ${ }^{1,}$, Thein Min Htike ${ }^{1}$ \\ Department of Mechanical Engineering, Yangon Technological University, Insein, Yangon, Myanmar
}

\section{ABSTRACT}

\begin{abstract}
Rotating unbalance is one of the main sources of vibration in a rotor system. Vibration due to unbalance may cause noise, decreased life of bearings, unsafe work conditions, and reduced machine life. Different methods have been studied on the identification of unbalance in the rotor system. This study aims to estimate the unbalance using frequency response function of the rotor system and operating deflection shape, i.e., vibration responses under the unbalance. Frequency response function is obtained by conducting eigen-analysis in MATLAB using equations of motion obtained by Jeffcott rotor model. The commercial finite element package, COMSOL Multiphysics software is used to model the rotor system with rotating unbalance and computes the forced vibration response. Frequency response function and frequency domain response are used to inverse estimate the rotating unbalance. The estimation error between estimated unbalances and corresponding prescribed values is lower than $0.1 \%$. This study also shows the use of COMSOL Multibody Dynamics module to simulate the vibration due to the rotating unbalance.
\end{abstract}

\section{Keywords:}

Rotating unbalance; vibration responses;

\section{Introduction}

Vibration is one of the main factors to be considered in designing, condition monitoring and control of rotating machinery. One of the main causes of vibration in rotating machinery is rotating unbalance and the rotor response to the unbalance can cause detrimental effect. If not properly maintained, the unbalance in the rotor system may cause high vibration and noise level, decreased life of bearings, unsafe work condition and reduced machine life. Therefore, it is important to identify the unbalance in a rotor system to prevent premature failure of the rotor system. There have been both traditional and modern methods to identify the unbalance in the rotating machinery.

Tai et al., [7] analysed steady state response of a single rub-impact rotor system. The harmonic balance method with pseudo arc-length continuation is used to obtain the analytical solutions of the stable periodic motion.

The changed of frequency response due to unbalance at first natural frequency was discussed. Nanfei Wang and Dongxiang Jiang [4] described vibration response characteristics of a dual rotor unbalance. The governing equation of dual rotor system with unbalance was numerically derived by

\footnotetext{
* Corresponding author.

E-mail address: mamyathethnin@gmail.com
}

https://doi.org/10.37934/aram.71.1.1123 
using Runge Kutta method. The rotor test rig model was conducted to experimentally validate the responses due to the rotating unbalance. Juan $\mathrm{Xu}$ et al., [6] presented vibration characteristics of unbalance responses for motorized spindle system using mathematical and simulation models at high excitation frequencies. For mathematical modelling, D'Alembert's Principle was used to derive the equation of motion and ANSYS was used to simulate the response. Apart from those studies on analysis of vibration response due to rotating unbalance, Sudhakar and Sekhar [8] identified unbalance fault in a rotor bearing system using equivalent loads minimization and vibration minimization method. Unbalance fault was experimentally identified for one rotating speed and three unbalance conditions. The maximum discrepancy was $23 \%$ in unbalance identification process. Using different method, Akash Shrivastava and Amiya Ranjan Mohanty [5] also identified unbalance in a rotor system. Three different rotating speeds and four unbalance conditions were presented using a joint input estimation. The maximum discrepancy between actual and estimated unbalance reported is $10 \%$.

The main aim of this study is to show the use of multibody dynamics module in COMSOL to simulate rotor vibration due to rotating unbalance and estimate the unbalance using the simulated ODS and FRF obtained by the theoretical Jeffcott model. The values of bearing stiffnesses are estimated using FEM model of a single rolling element and analytical equations without the need of iteration. For obtaining ODS, the vibration responses due to unbalance, COMSOL Multiphysics package is used. Finally, the unbalance is estimated using the relationship between FRF and ODS, and then the estimated value is compared with pre-introduced values.

\section{Methodology}

Frequency response function (FRF) is the ratio between vibration responses of a structure and excitation force acting on it at different frequencies. The flow chart in Fig. 1 shows the procedure for calculating FRF, simulating ODS and estimating the unbalance on the rotor.

The rotor system used in this study is shown in Fig. 2. The disc is placed at midspan of the shaft and the shaft is supported by the two deep groove ball bearings. The equation of motion for the system is derived using Langrange approach.

$$
\frac{\mathrm{d}}{\mathrm{dt}}\left(\frac{\partial \mathrm{T}}{\partial \dot{\mathrm{q}}_{\mathrm{i}}}\right)-\frac{\partial \mathrm{T}}{\partial \mathrm{q}_{\mathrm{i}}}+\frac{\partial \mathrm{V}}{\partial \mathrm{q}_{\mathrm{i}}}=\mathrm{Q}_{\mathrm{i}}
$$

where $T$ and $V$ are kinetic and potential energy functions respectively, and $q_{i}$ and $Q_{i}$ are the generalized coordinates and forces, respectively. 


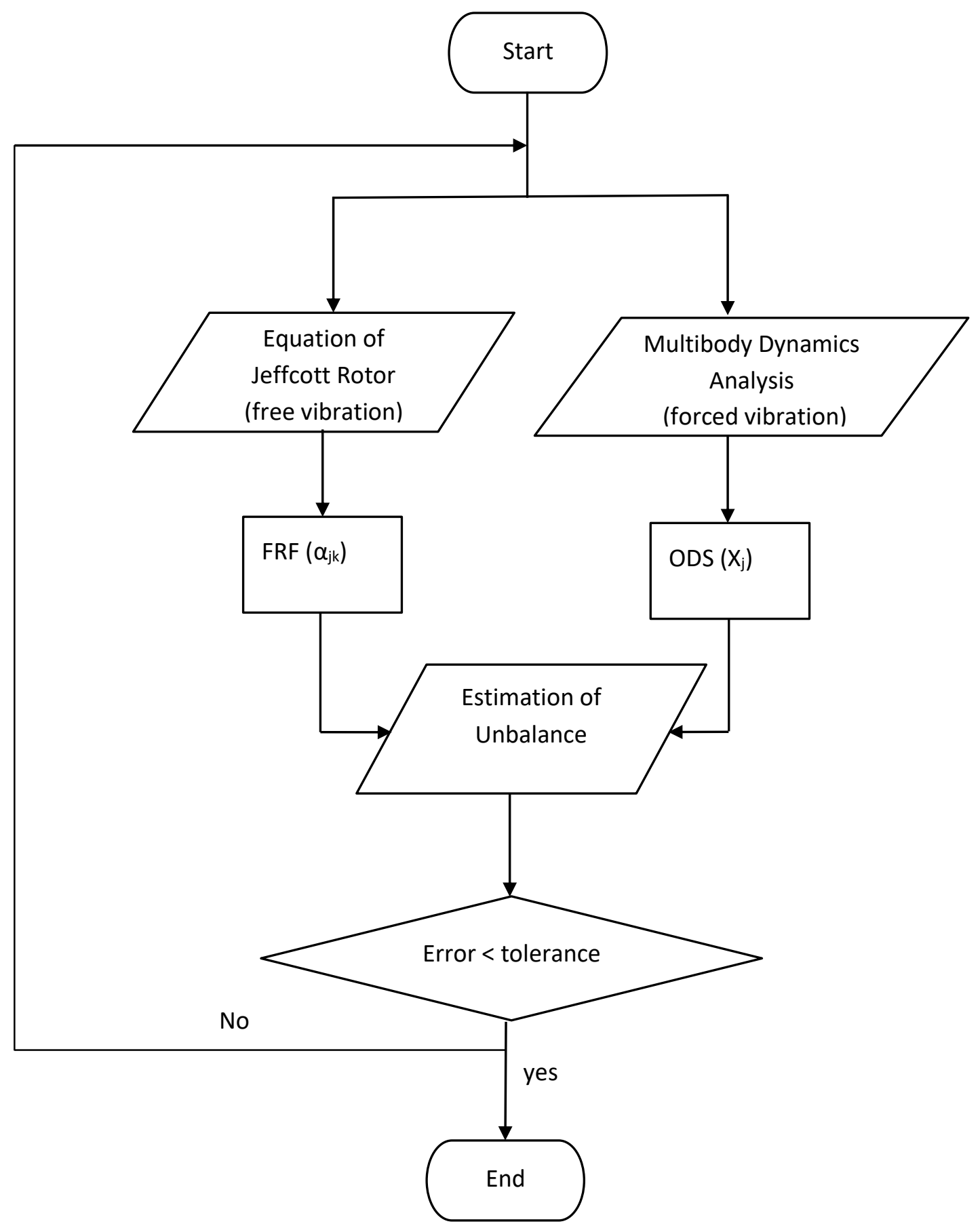

Fig. 1. Unbalance Estimation Procedure<smiles>[Y]C1CC1C</smiles>

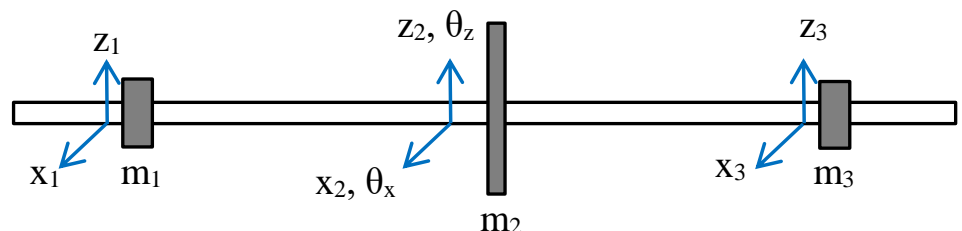

Fig. 2. Schematic diagram of simple rotor system 


\subsection{Calculating FRF of the Rotor System}

The equations of motion for the model shown in Fig. 1 is presented in matrix form as follows. Frequency response function is obtained by eigenvalue analysis and modal analysis of the rotor system. MATLAB software is used to compute FRF.

$$
\begin{aligned}
{\left[\begin{array}{cccccccc}
m_{1} & 0 & 0 & 0 & 0 & 0 & 0 & 0 \\
0 & m_{1} & 0 & 0 & 0 & 0 & 0 & 0 \\
0 & 0 & m_{2} & 0 & 0 & 0 & 0 & 0 \\
0 & 0 & 0 & m_{2} & 0 & 0 & 0 & 0 \\
0 & 0 & 0 & 0 & I_{T} & 0 & 0 & 0 \\
0 & 0 & 0 & 0 & 0 & I_{T} & 0 & 0 \\
0 & 0 & 0 & 0 & 0 & 0 & m_{3} & 0 \\
0 & 0 & 0 & 0 & 0 & 0 & 0 & m_{3}
\end{array}\right]\left\{\begin{array}{l}
\ddot{x}_{1} \\
\ddot{z}_{1} \\
\ddot{x}_{2} \\
\ddot{z}_{2} \\
\ddot{\theta}_{x} \\
\ddot{\theta}_{z} \\
\ddot{x}_{3} \\
\ddot{z}_{3}
\end{array}\right\}+\left[\begin{array}{cccccccc}
0 & 0 & 0 & 0 & 0 & 0 & 0 & 0 \\
0 & 0 & 0 & 0 & 0 & 0 & 0 & 0 \\
0 & 0 & 0 & 0 & 0 & 0 & 0 & 0 \\
0 & 0 & 0 & 0 & 0 & 0 & 0 & 0 \\
0 & 0 & 0 & 0 & 0 & I_{p} \omega & 0 & 0 \\
0 & 0 & 0 & 0 & I_{p} \omega & 0 & 0 & 0 \\
0 & 0 & 0 & 0 & 0 & 0 & 0 & 0 \\
0 & 0 & 0 & 0 & 0 & 0 & 0 & 0
\end{array}\right]\left\{\begin{array}{l}
\dot{x}_{1} \\
\dot{z}_{1} \\
\dot{x}_{2} \\
\dot{z}_{2} \\
\dot{\theta}_{x} \\
\dot{\theta}_{z} \\
\dot{x}_{3} \\
\dot{z}_{3}
\end{array}\right\} } \\
\\
+
\end{aligned}
$$

where,

$\mathrm{m}_{1}=$ mass of left bearing, $\mathrm{kg}$

$\mathrm{m}_{2}=$ mass of disc, $\mathrm{kg}$

$\mathrm{m}_{3}=$ mass of right bearing, $\mathrm{kg}$

$\mathrm{I}_{\mathrm{T}}=$ transverse moment of inertia, $\mathrm{kg}-\mathrm{m}$

$I_{\mathrm{P}}=$ polar moment of inertia, $\mathrm{kg}-\mathrm{m}$

$\mathrm{K}_{\mathrm{xx}}=$ bearing stiffness at $\mathrm{X}$ axis, $\mathrm{N} / \mathrm{m}$

$\mathrm{K}_{\mathrm{zz}}=$ bearing stiffness at $\mathrm{Z}$ axis, $\mathrm{N} / \mathrm{m}$

$\mathrm{K}_{\mathrm{xz}}=$ bearing stiffness at $\mathrm{X}-\mathrm{Z}$ axis, $\mathrm{N} / \mathrm{m}$

\subsection{Bearing Stiffness Calculation}

Bearing stiffness is one of the important parameters in the rotor system and hence its characterize dynamic properties of the system. Inaccuracy in bearing stiffness will result in inaccuracy in both FRF and ODS. There are many approaches to calculate the bearing stiffness but most them require complex iterative procedure to determine the stiffness. In this study, bearing stiffness is computed based on load-deflection curve of the bearing. A single rolling element bearing is modeled in COMSOL Multiphysics as shown in Fig. 3 and load-deflection curve is generated. The specifications of single deep grooved ball bearing used in this study are shown in Table 1. 


\section{Table 1}

Bearing Specifications

\begin{tabular}{cc}
\hline Description & Value \\
\hline Bearing model & $608 \mathrm{z}$ \\
Outer diameter & $22 \mathrm{~mm}$ \\
Inner diameter & $8 \mathrm{~mm}$ \\
Number of balls & 8 \\
Thickness & $7 \mathrm{~mm}$ \\
Ball diameter & $4 \mathrm{~mm}$ \\
Contact angle & $45 \mathrm{deg}$ \\
\hline
\end{tabular}

In this simulation, the load acting on the bearing is considered to vary from 100 to $1000 \mathrm{~N}$ in a step of $100 \mathrm{~N}$ based on reported value in the literature [2]. Load is acting on the bearing at the point of contact which is inclined by contact angle of $45^{\circ}$. Because the maximum load rate of bearing for this study is $1370 \mathrm{~N}$ [11]. After obtaining the deflection $\delta_{r}$, the load distribution factor and the load deflection factor are calculated using Equations (4) and (5). Next, the bearing stiffness $K_{x x}, K_{z z}, K_{z x}$ are obtained from the curve between $100 \mathrm{~N}$ and $1000 \mathrm{~N}$ force using equation (5) and (6). The stiffness at $500 \mathrm{~N}$ load will be used in this study because the fatigue load rating for this bearing is $570 \mathrm{~N}$.
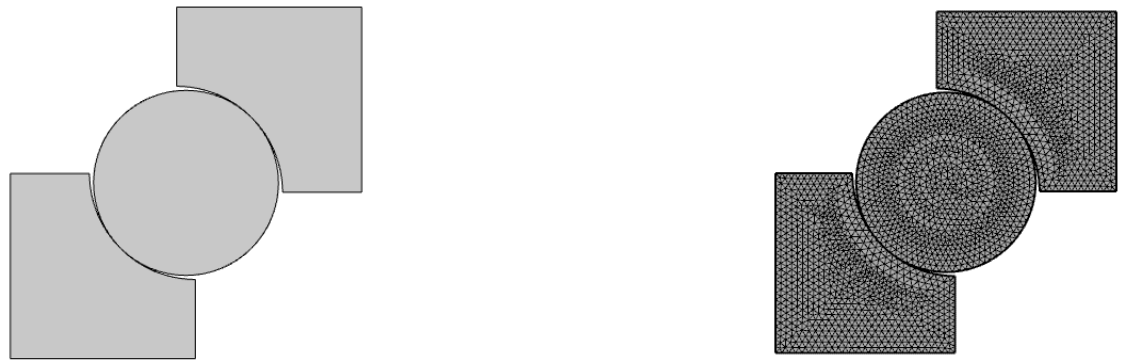

Fig. 3. Geometry and mesh of bearing cross section

$\varepsilon=\frac{1}{2}\left(1+\frac{\delta_{\mathrm{x}} \tan \alpha}{\delta_{\mathrm{r}}}\right)$

Where,

$\varepsilon=$ load distribution factor

$\delta_{\mathrm{x}}=$ axial deflection

$\delta_{r}=$ radial deflection

$\alpha=$ contact angle

$\mathrm{k}=10^{5} \times \mathrm{D}^{1 / 2}$

Where,

$\mathrm{k}=$ load deflection factor

$\mathrm{D}=$ ball diameter

$K_{\varepsilon}=Z k\left(\delta_{x} \sin \alpha+\delta_{r} \cos \alpha\right)^{n-1}$

Where,

$\mathrm{K}_{\varepsilon}=$ general term which is used in all the stiffness elements

$\mathrm{Z}=$ number of ball

$k=$ load deflection factor 


$$
\begin{aligned}
& \delta_{\mathrm{x}}=\text { axial deflection } \\
& \delta_{\mathrm{r}}=\text { radial deflection } \\
& \alpha=\text { contact angle } \\
& k_{\mathrm{xx}}=K_{\varepsilon} \sin ^{2} \alpha \\
& k_{\mathrm{xy}}=K_{\varepsilon} \sin \alpha \cos \alpha \\
& k_{\mathrm{yy}}=K_{\varepsilon} \cos ^{2} \alpha
\end{aligned}
$$

\subsection{Simulation of ODS due to Unbalance}

Operating deflection shapes (ODS) is any forced motion of two or more points on a structure which can be described either in frequency or in time domain. ODSs are used for visualization of the vibration pattern of a structure under real life operating conditions. It can be used to measure, display and animate the absolute dynamic response of structure, machine and their components. In this paper, the numerical simulation of ODS is done for simple rotor model which is considered for three unbalance conditions at various speeds. Multibody Dynamics module in COMSOL Multiphysics FEM package was used to simulate ODS. In this analysis, the rotating speed considered varies between 500 and $900 \mathrm{rpm}$ with an increment $100 \mathrm{rpm}$. ODS responses are obtained for three different unbalance conditions with 5, 10 and $15 \mathrm{~g}$ unbalance mass at eccentricity of $0.0095 \mathrm{~m}$. The material properties of a simple rotor system are shown in Table 2. The disc properties such as mass of disc, moment of inertia, eccentricity and phase are set in the simulation. The geometry of rotor is shown in Fig. 4 and the mesh of rotor is shown in Fig. 5. Unbalance mass is located at the $60^{\circ}$ from z-axis and the unbalance load is shown in Fig. 6 with the location of the bearing. Simulations are conducted for five excitation frequencies. Then, the ODS intime domain is collected and Fourier transform is applied to ODS to obtain frequency domain ODS.

Table 2

Material properties

\begin{tabular}{cc}
\hline Shaft & Disc \\
\hline Steel & Steel \\
Length $=300 \mathrm{~mm}$ & Diameter $=100 \mathrm{~mm}$ \\
Diameter $=8 \mathrm{~mm}$ & Thickness $=5 \mathrm{~mm}$ \\
$\mathrm{E}=2 \times 10^{11} \mathrm{~N} / \mathrm{m}^{2}$ & $\mathrm{E}=2 \times 10^{11} \mathrm{~N} / \mathrm{m}^{2}$ \\
Density $=7800 \mathrm{~kg} / \mathrm{m}^{3}$ & Density $=7800 \mathrm{~kg} / \mathrm{m}^{3}$ \\
Poisson's ratio $=0.3$ & Poisson's ratio $=0.3$ \\
\hline
\end{tabular}


$-0.05$
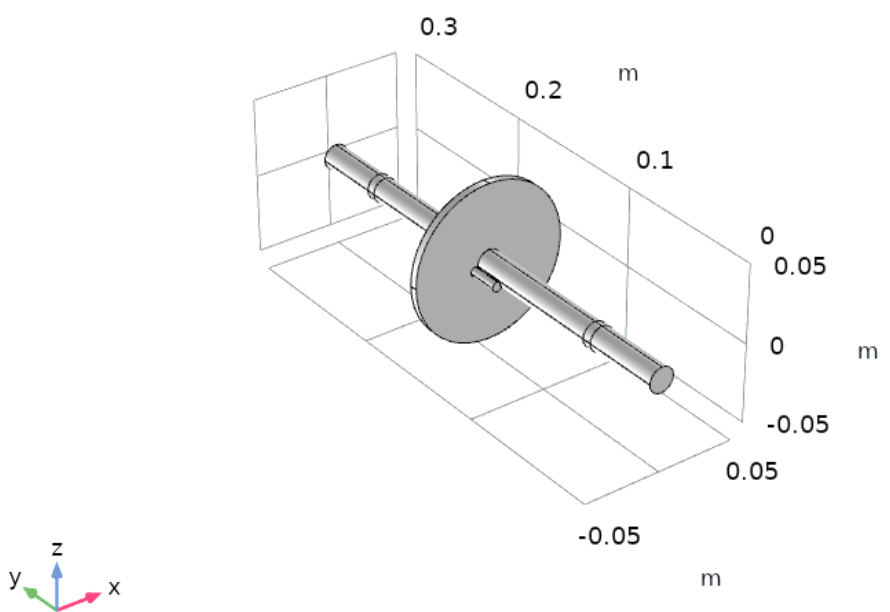

Fig. 4. Geometry of rotor

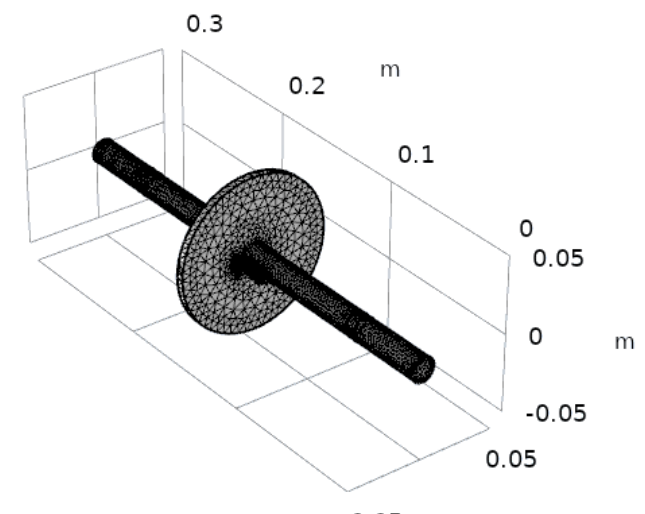

$-0.05$

Fig. 5. Mesh of rotor

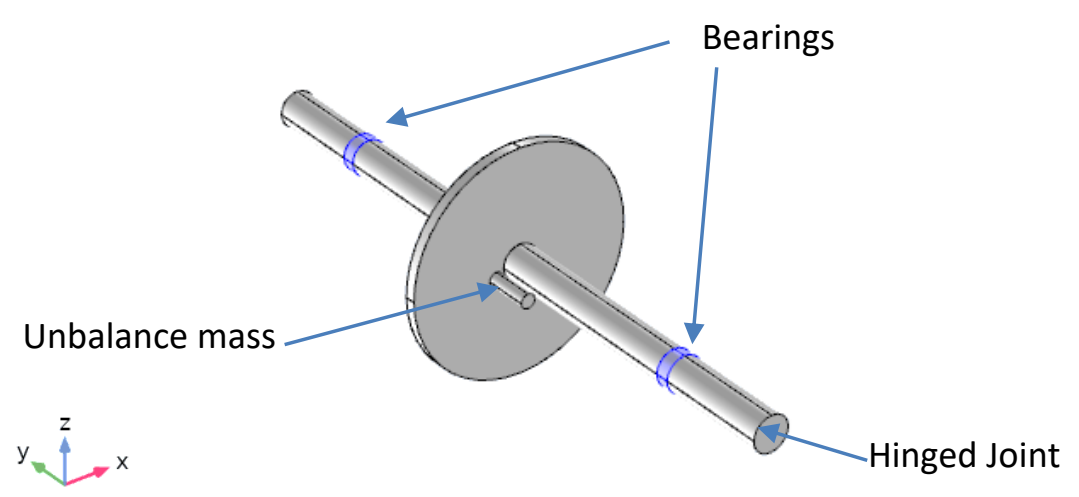

Fig. 6. Boundary conditions of rotor

\subsection{Method of Unbalance Estimation}

ODS obtained in (2.3) is used to estimate the unbalance force together with FRF obtained by (2.1). The unbalance force can be estimated by using the following equation in an inverse way of force estimation using dynamic characteristics of the system (FRF) and forced response (ODS).

$$
\begin{aligned}
& \alpha(\omega)=\frac{X(\omega)}{F(\omega)} \\
& \{F(\omega)\}_{n_{1} \times 1}=[\alpha(\omega)]_{n_{1} \times n_{2}}^{-1}\{X(\omega)\}_{n_{2} \times 1}
\end{aligned}
$$

Where,

$[\alpha(\omega)]=$ FRF matrix

$\{F(\omega)\}=$ Force vector

$\{X(\omega)\}=$ Displacement response (ODS)

The centrifugal force generated by unbalance is expressed as follow [1]. Magnitude of unbalance, $m e$ (N.m) is calculated. This can be used to computer counter-balancing mass at desired eccentricity.

$\mathrm{F}=\mathrm{me} \omega^{2}$

Where,

$\mathrm{F}=$ unbalance force, $\mathrm{N}$ 
$\mathrm{m}=$ unbalance mass, $\mathrm{kg}$

$\omega=$ excitation frequency, $\mathrm{rad} / \mathrm{s}$

\section{Results and Discussion}

The bearing stiffness obtained by the procedure in (2.2) is shown in Fig. 7. As shown in the Figure, the stiffness varies non-linearly with the load. In practice, the bearing stiffness changes with the load it bears and the deflection at that load. However, for the analysis in this study, the stiffness at $500 \mathrm{~N}$ load was considered because it is the expected load on the bear near the bearing fatigue load limit, $570 \mathrm{~N}$. The results on the bearing stiffnesses are tabulated in Table 3. These values were used in calculating FRFs of the rotor system.

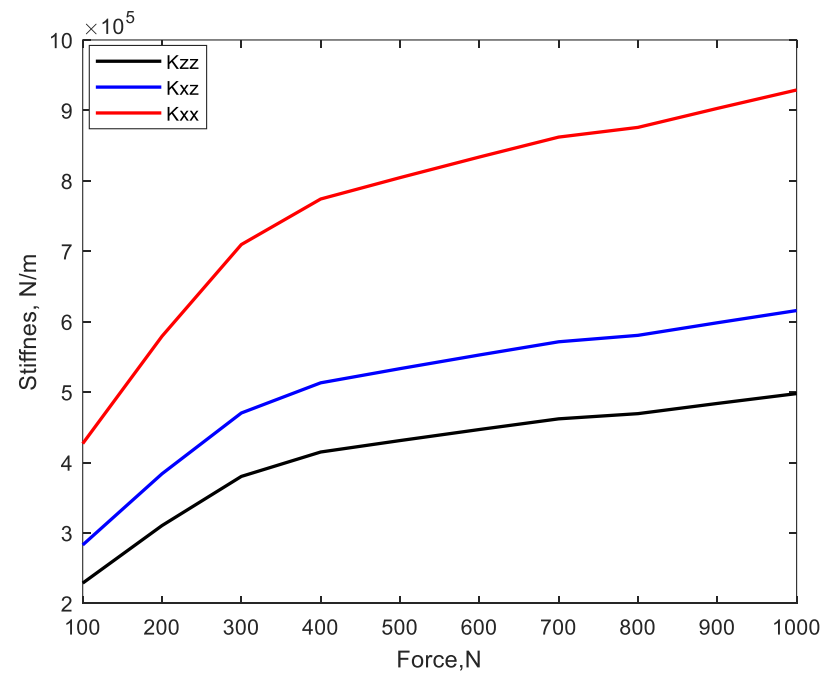

Fig. 7. Force and stiffness curve for bearing

Table 3

Components of bearing stiffness

\begin{tabular}{lcc}
\hline $\mathrm{K}_{\mathrm{xx}}(\mathrm{N} / \mathrm{m})$ & $\mathrm{K}_{2 \mathrm{x}}(\mathrm{N} / \mathrm{m})$ & $\mathrm{K}_{\mathrm{Zz}}(\mathrm{N} / \mathrm{m})$ \\
\hline $4 \times 10^{5}$ & $5 \times 10^{5}$ & $8 \times 10^{5}$ \\
\hline
\end{tabular}

\subsection{Results on Frequency Response Function}

Selected frequency response functions, $\alpha_{31}, \alpha_{32}, \alpha_{33}$, and $\alpha_{34}$ obtained by eigenvalue analysis and modal analysis are shown in Fig. 8 (a). As seen in the figure, the natural frequencies of the rotor system can be seen at the peak responses. Corresponding changes in the phase angle as shown in Fig. 8 (b) also confirm the resonance behaviour. 

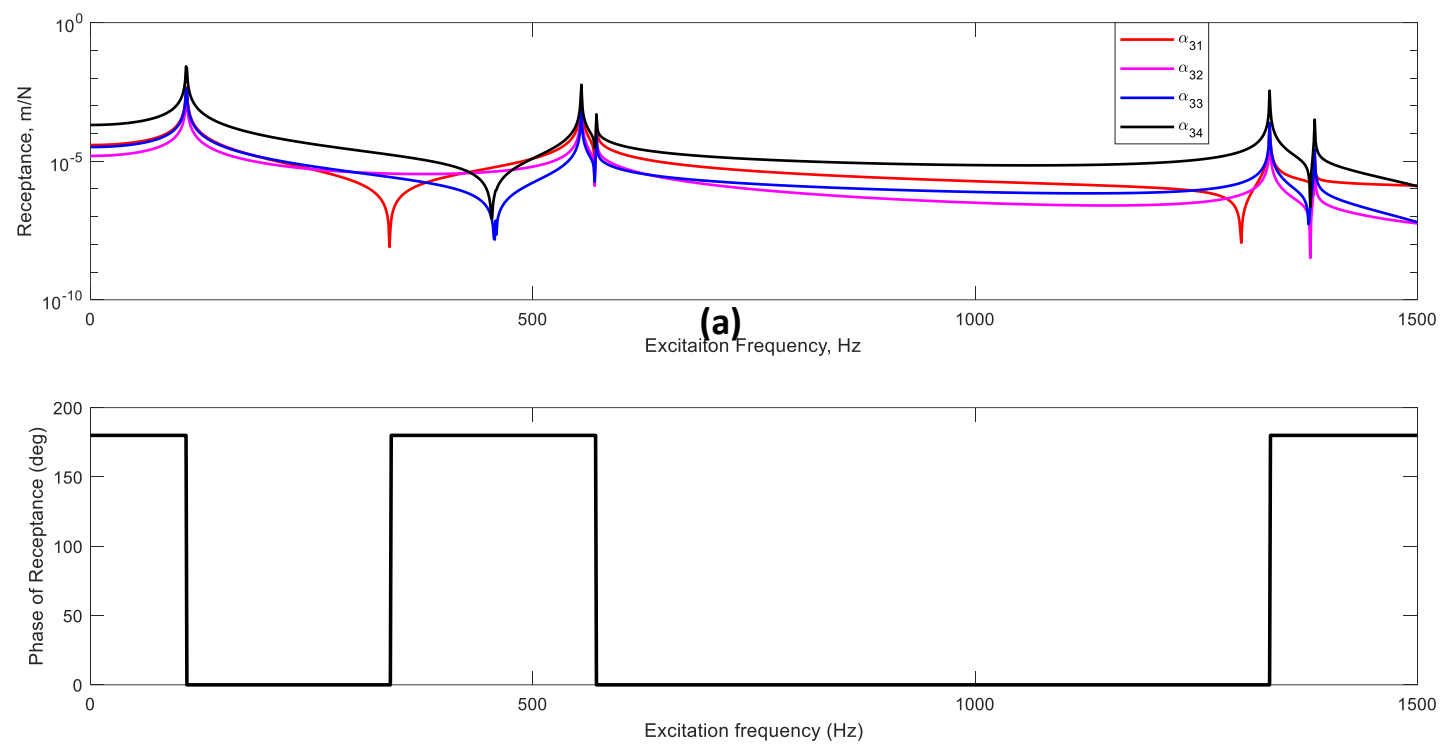

(b)

Fig. 8. Frequency response function (a) magnitude, and (b) phase

\subsection{Results on Operating Deflection Shape}

Total displacement of rotor under the rotating unbalance of $5 \mathrm{~g}$ at rotational speed of $500 \mathrm{RPM}$ is shown in Fig. 9. The maximum deformation occurs in rotor disc due to unbalance mass. The result of unbalance effect on vibration responses is shown in Fig. 10. It can be seen that magnitude of vibration amplitudes significantly increases with excitation frequency. The responses at time domain are shown in Fig. 11.

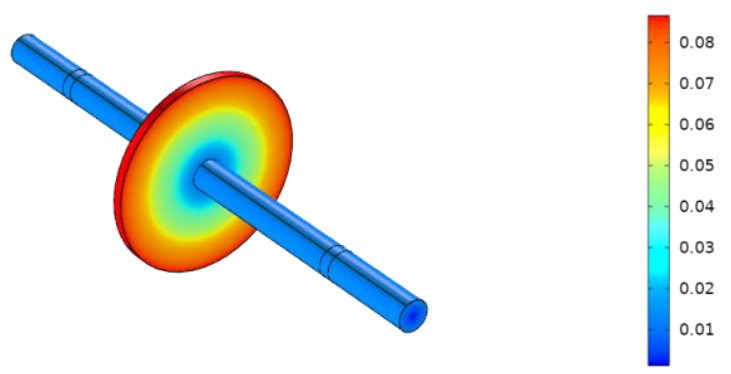

Fig. 9. Total displacement deformation 

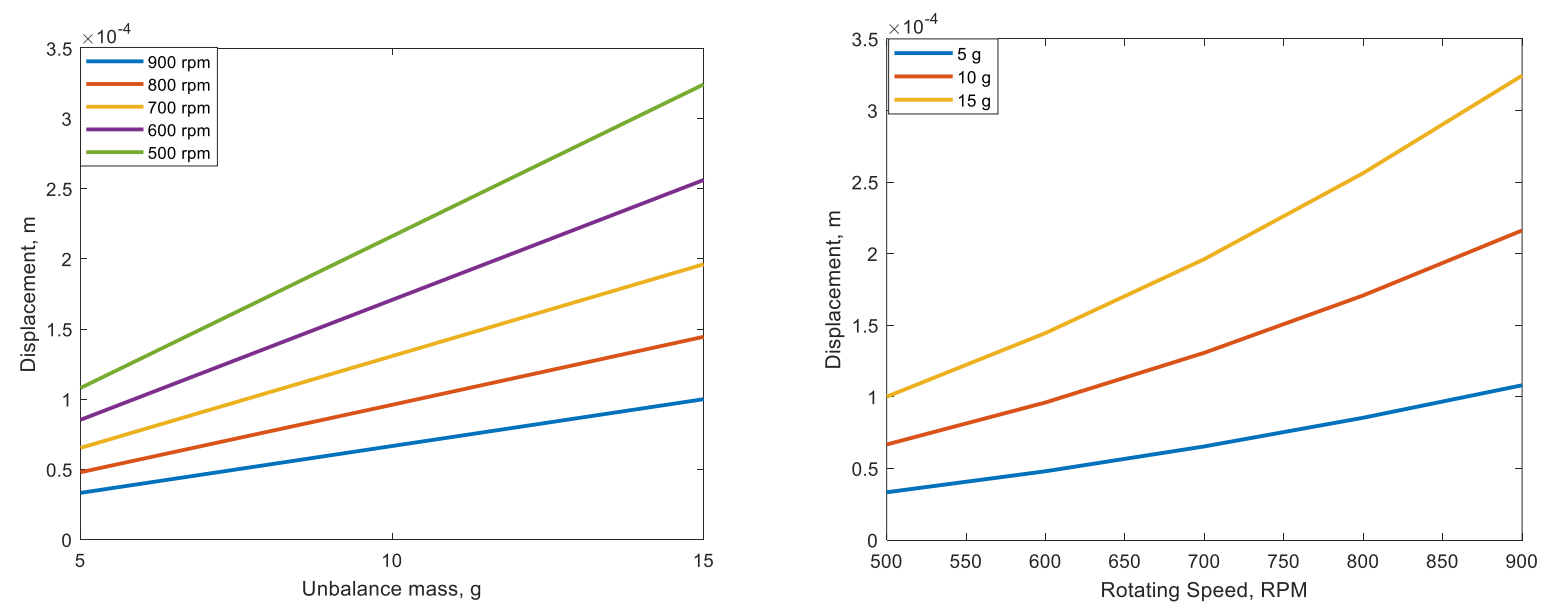

Fig. 10. Effect of unbalance and rotating speed on vibration responses

As expected, simulation results show that the linear variation of the vibration displacement response with the magnitude of the unbalance and the square variation of the vibration displacement response with the rotating speed.

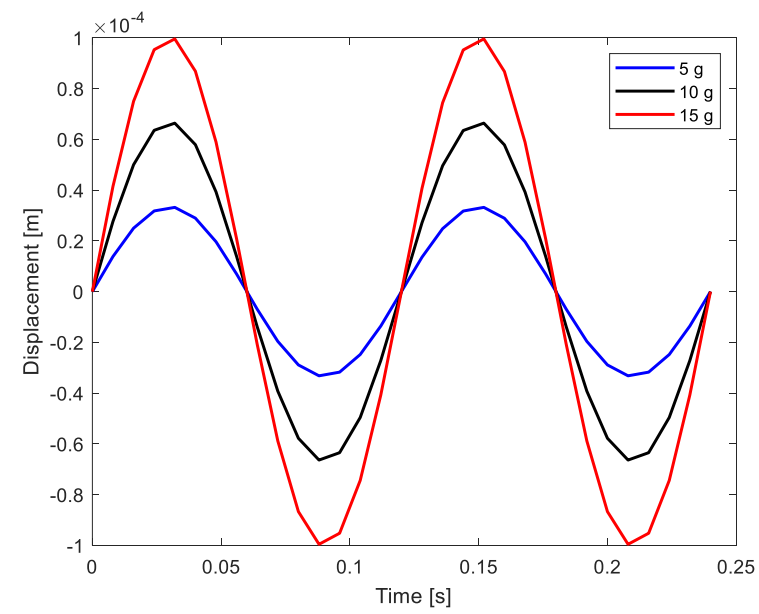

(a)

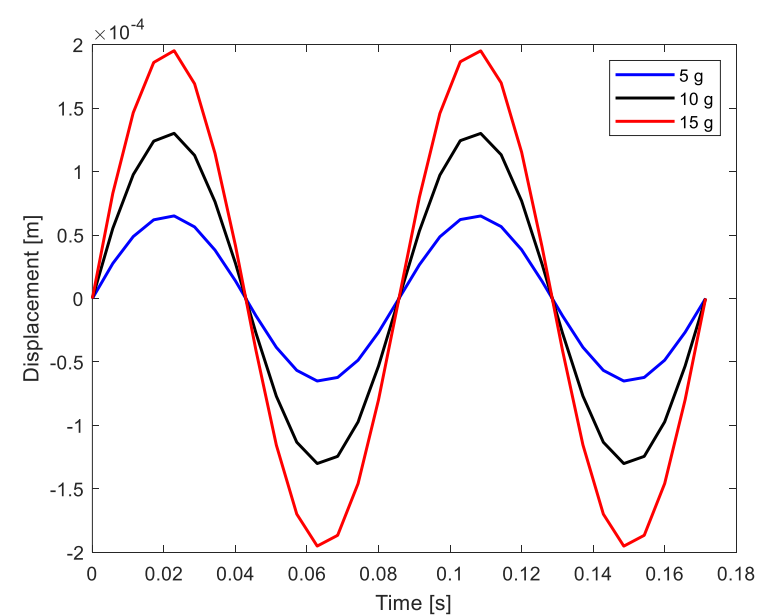

(c)

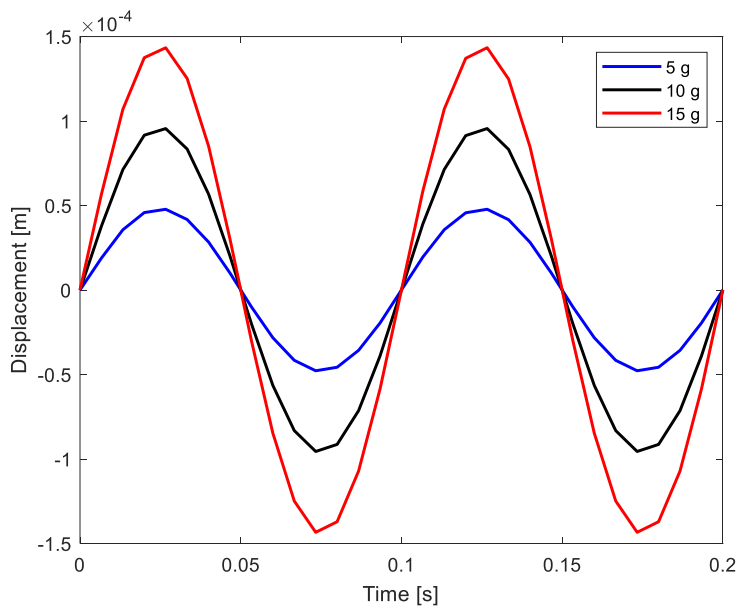

(b)

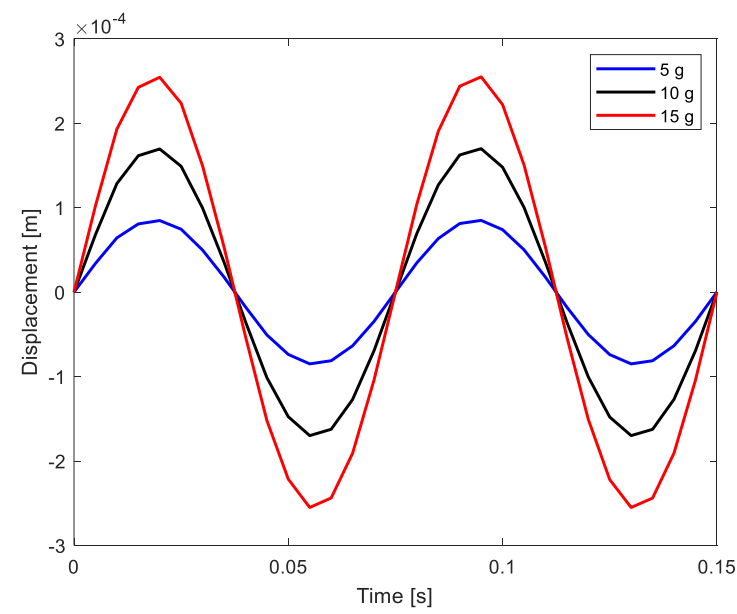

(d) 


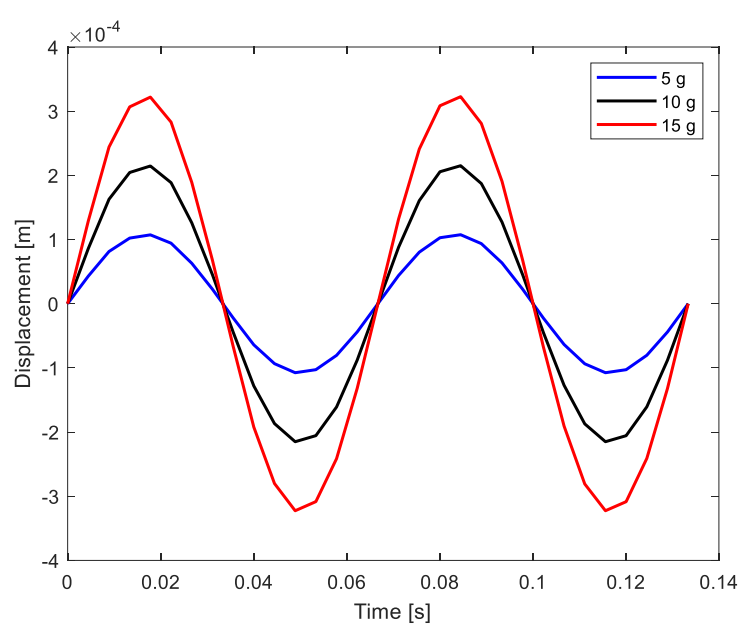

(e)

Fig. 11. Unbalance responses at time domain (a) $500 \mathrm{rpm}$, (b) $600 \mathrm{rpm}$, (c) $700 \mathrm{rpm}$, (d) $800 \mathrm{rpm}$ and, (e) 900 rpm

\subsection{Estimation of Rotating Unbalance Results}

Frequency response function and operating deflection shape are used to estimate unbalance in rotor bearing system using equation (7). The estimation of unbalance is discussed at five rotating speeds and three unbalance conditions. The estimated results of three unbalance mass at $500 \mathrm{rpm}$ is shown in Fig. 12. The results of unbalance estimation under different unbalance and rotational speeds are shown in Table 3. It can be clearly seen that estimated unbalance at the operating speed of the rotor system appear only at the first harmonic of the rotational speed. This is expected since the unbalance force oscillates with the rotation. It can be concluded that the FRFs and ODSs can be used effectively for estimating unbalance force.

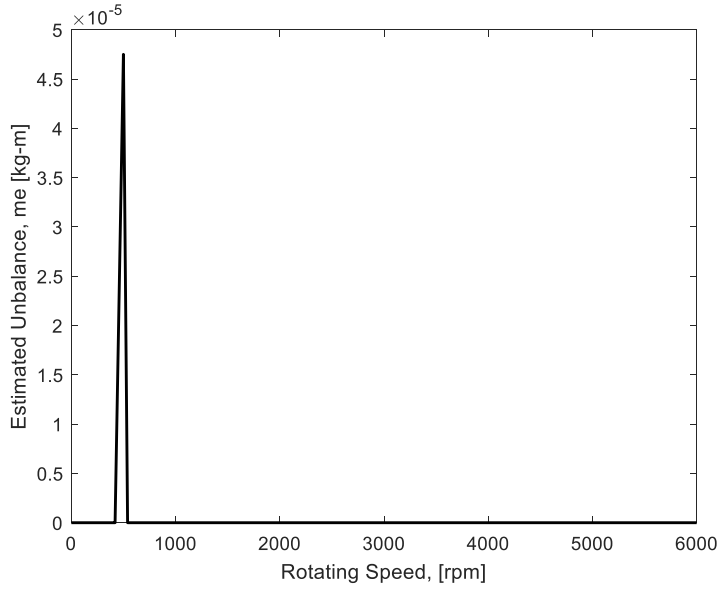

(a)

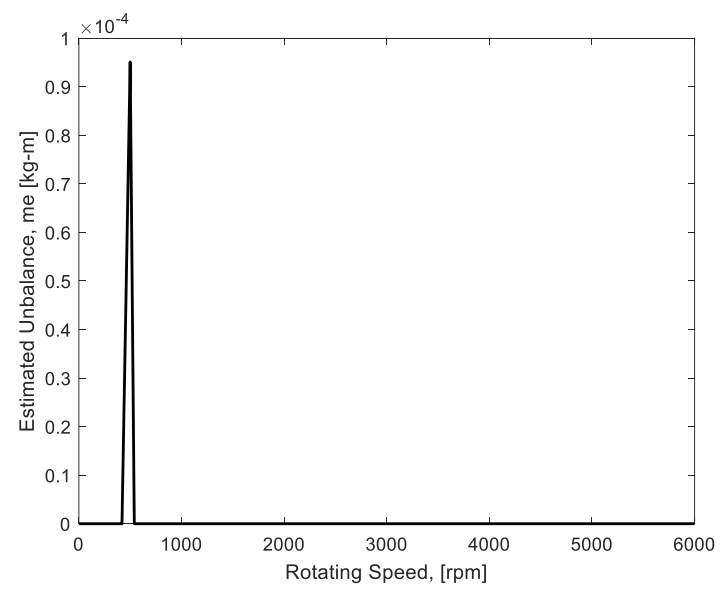

(b) 


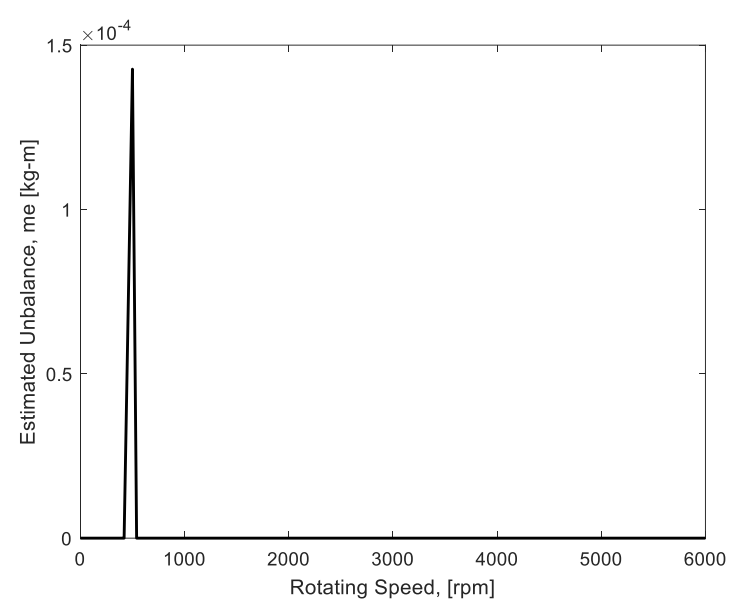

(c)

Fig. 12. Unbalance estimation result for(a) $5 \mathrm{~g}$, (b) $10 \mathrm{~g}$, and (c) $15 \mathrm{~g}$ at $500 \mathrm{rpm}$

\section{Table 3}

Comparison of introduced and estimated unbalance

\begin{tabular}{cccc}
$\begin{array}{c}\text { Rotating Speed } \\
(\mathrm{rpm})\end{array}$ & $\begin{array}{c}\text { Introduced Unbalance } \\
\left(\mathrm{me}, 10^{-5} \mathrm{~kg}-\mathrm{m}\right)\end{array}$ & $\begin{array}{c}\text { Estimated Unbalance (me, } \\
\left.10^{-5} \mathrm{~kg}-\mathrm{m}\right)\end{array}$ & Discrepancy (\%) \\
500 & 4.757 & 4.755 & 0.042 \\
& 9.514 & 9.513 & 0.011 \\
& 14.271 & 14.270 & 0.007 \\
& & & \\
600 & 4.757 & 4.753 & 0.084 \\
& 9.514 & 9.515 & 0.021 \\
& 14.271 & 14.270 & 0.007 \\
700 & 4.757 & 4.756 & 0.021 \\
& 9.514 & 9.513 & 0.011 \\
& 14.271 & 14.270 & 0.007 \\
800 & 4.757 & & \\
& 9.514 & 4.755 & 0.042 \\
& 14.271 & 9.516 & 0.021 \\
& & 14.263 & 0.056 \\
900 & 4.757 & & 0.021 \\
& 9.514 & 4.758 & 0.021 \\
& 14.271 & 9.515 & 0.035 \\
\hline
\end{tabular}

Table shows inversely estimated unbalance and the introduced values. As seen in the Table, the maximum discrepancy is only $0.084 \%$ even though the differences in modelling the bearing in computing FRF and ODSs. While bearing stiffness estimated by theoretical equations in combination with FEM model was used for FRF computation, the rolling element bearings were directly modelled without imposing the numerical values. The high accuracy results in determining the unbalance show that the bearing model by both approaches are justified. 


\section{Conclusions}

In this study, the estimation of unbalance using frequency response function of the rotor system and operating deflection shape has been proposed. Unbalance has been estimated for five rotating speeds and three unbalance mass. Based on the results, the following conclusion can be drawn.

(1)The rotating unbalance in the rotor system can be estimated by using inverse method with FRFs and ODS. The maximum discrepancy between estimated unbalance and corresponding prescribed value is $0.084 \%$ showing high accuracy of estimation.

(2)Stiffness values of the rotating element bearing can be computed based on the deflection of a single element using FEM model.

The results can be beneficial in the maintenance of industrial machines to estimate rotating unbalance from FRF and ODS data. Once the bearing stiffnesses are obtained, FRF can be computed and serve as a basis for the inverse estimation. ODS can be measured directly on the bearing and using the two of them, unbalance can be estimated online. Therefore, further study should focus the use of this method for the inverse online estimation of the unbalance. The method should be extended to inversely estimate multiple excitation sources which can be the combination of at least the two of the unbalances in two or more planes, shaft misalignment and gear rattle.

\section{References}

[1] Singiresu S. Rao. "Mechanical vibration."fifth edition, Prentice Hall, (2011).

[2] Rijnberg, J. L. "Theoretical modeling of the stiffness of angular contact ball bearings using a two DOF and a five DOF approach." DCT rapporten 2007 (2007).

[3] Ahobal, N. "Study of vibration characteristics of unbalanced overhanging rotor." In IOP Conference Series: Materials Science and Engineering, vol. 577, no. 1, p. 012140. IOP Publishing, 2019. https://doi.org/10.1088/1757-899X/577/1/012140

[4] Wang, Nanfei, and Dongxiang Jiang. "Vibration response characteristics of a dual-rotor with unbalancemisalignment coupling faults: theoretical analysis and experimental study." Mechanism and Machine Theory 125 (2018): 207-219. https://doi.org/10.1016/i.mechmachtheory.2018.03.009

[5] Shrivastava, Akash, and Amiya R. Mohanty. "Identification of unbalance in a rotor system using a joint input-state estimation technique." Journal of Sound and Vibration 442 (2019): 414-427. https://doi.org/10.1016/j.jsv.2018.11.019

[6] Xul, Juan, Xuehui Zheng, Jianjun Zhang, and Xuan Liu. "Vibration characteristics of unbalance response for motorized spindle system." Procedia engineering 174 (2017): 331-340.

https://doi.org/10.1016/i.proeng.2017.01.148

[7] Tai, Xingyu, Hui Ma, Fuhao Liu, Yang Liu, and Bangchun Wen. "Stability and steady-state response analysis of a single rub-impact rotor system." Archive of Applied Mechanics 85, no. 1 (2015): 133-148. https://doi.org/10.1007/s00419-014-0906-2

[8] Sudhakar, G. N. D. S., and A. S. Sekhar. "Identification of unbalance in a rotor bearing system." Journal of Sound and Vibration 330, no. 10 (2011): 2299-2313. https://doi.org/10.1016/i.jsv.2010.11.028

[9] Maurice Jr, L. Rotating machinery vibration: from analysis to troubleshooting. Marcel Dekker, 2000.

[10] Hernot, X., M. Sartor, and J. Guillot. "Calculation of the stiffness matrix of angular contact ball bearings by using the analytical approach." J. Mech. Des. 122, no. 1 (2000): 83-90. https://doi.org/10.1115/1.533548

[11] https://www.skf.com/us/search-results?q=608z\&searcher=all\&site=327\&language=en 